\title{
Research on Translation Strategies in the Process of Translation
}

\author{
Saihanqiqige \\ Chifeng University Press Agency \\ Inner Mongolia Chifeng 024000
}

\begin{abstract}
In this paper, 30 college students majoring in English from Chifeng University are selected as research objects. By means of the think-aloud protocols, this paper makes an empirical study on the translation strategies used by students in the process of translation, and analyzes the number, frequency and segment information of the specific translation strategies used in the process of translation, so as to further explain the reasons that affect students' choice of translation strategies.
\end{abstract}

Keywords-Translation process; Think-aloud protocols; Translation strategy

\section{INTRODUCTION}

Translation plays an extremely important role in social development. In the past, many scholars focused their attention on the study of translated works from different theoretical perspectives, and few scholars have paid attention to the study of translation process. However, with the development of linguistics, there are more and more experimental researches on the process of cognitive translation. In this paper, taking the translation process of Kiraly's psychological language model as the theoretical basis, through the think-aloud protocols, the data is collected and coded to extract the translation strategies used by the students in the process of translation. Through questionnaires, students' psychological activities in the process of translation are further understood, and the reasons why they choose different translation strategies are analyzed.

\section{A BRIEF INTRODUCTION TO THINK-ALOUD PROTOCOLS}

The think-aloud protocols can be also known as the "thinkaloud analysis protocols, which are abbreviated as TAPs. As early as the beginning of the 20th century, the TAPs were widely used in psychological experiments, clinical thinking research and children's thinking research. Subsequently, relevant scholars began to apply the think-aloud protocols in the field of language research, such as the second language acquisition and language learning. When a person is speaking, he must be thinking. From this point of view, the think-aloud protocols can record the cognitive thinking activity of the translator in the process of translation, and record the thinking process of the translator's brain, so as to analyze the translator's brain working state and the various factors that affect the translation.

At the end of the 1980s, the think-aloud protocols began to prevail in the field of translation. Scholars began to conduct an empirical study based on the think-aloud protocols. At the same time, in order to obtain more extensive think-aloud data, scholars further used introspective techniques such as retrospective analysis, timing annotations, post test interviews, and questionnaire surveys, and in order to obtain reliable and effective data, Translog(a computer program that records the input process of the text keyboard), the professional screen video and eye tracking technologies were used to strengthen the authenticity of the experiment.

According to the previous translation studies based on the think-aloud protocols, the domestic and foreign scholars mainly focus on four aspects, namely, translation strategies, translation units, translation concepts and translation models. At the same time, in this process, scholars have demonstrated many factors that affect translation, such as psychological factors, automation, and the different materials that are referred to during the translation.

\section{THE PSYCHOLOGICAL LANGUAGE MODEL OF KIRALY'S TRANSLATION PROCESS}

In 1997, Kiraly proposed the psychological language model of the translation process, and obtained the strategies used by German students in the process of English and German translation. In the process of translation, a series of activities in the mind of the translators further expanded the scope of the study of the translation process. Kiraly's 20 translation strategy indicators and corresponding symbols are as follows: 
TABLE I. STRATEGY INDICATORS OF KIRALY’s MODEL(1997)

\begin{tabular}{ll}
\hline Representative symbol & \multicolumn{1}{c|}{ Meaning } \\
\hline S1 & Accept the internal solution \\
S2 & Try syntactic reconstruction \\
S3 & Back translation \\
S4 & Abort the attempt \\
S5 & Stop translation and start again \\
S6 & Use memory help \\
S7 & Find the problem \\
S8 & Query source language -- target language dictionary \\
S9 & Out of language judgment \\
S10 & Intuition judgment \\
S11 & Monitor the accuracy of the target language text \\
S12 & Query target language- source language dictionary \\
S13 & Select the dictionary entry \\
S14 & Reorganize context \\
S15 & Delete semantics \\
S16 & Consider the expectation of translation \\
S17 & Explain the source language text \\
S18 & Uncertainty about the acceptability of text \\
S19 & Automatically output text \\
S20 & Invalid dictionary query
\end{tabular}

This study, in addition to judging whether Chinese students have used the translation strategies proposed by Kiraly and which translation strategies they have used, focuses on whether Chinese students have used other translation strategies.

\section{EXPERIMENTAL DESIGN}

The experimental design included four aspects: the subjects, the experimental materials, the experimental process and the experimental data collection.

(1)This experiment mainly aimed at the college students majoring in English, therefore, 30 third-year English majors form Chifeng University were selected as subjects in this study. The reasons were as follows: The first was that their native language was Chinese. The second was that they had received two years of translation course. The third was that 30 subjects had passed the TEM-4 and had a certain English foundation.

(2) The two materials selected in the experiment were all from the simulated test of TEM-4. One was about introducing Taiwan and was a material of prose nature. The main feature of this material was that it contained many words with cultural significance, and there were many factors to be considered in translation. The second material was a relatively independent paragraph, indicating that the nature article did not need to take into account the context. The two articles were moderately difficult, however, it was enough to cover many problems in translation, and the students' ability and strategies to deal with problems in the process of translation from different angles can be seen.
(3) The Experiment was Divided into Two Stages: Preparation Stage and Implementation Stage.

Preparation stage: The author first read a large amount of relevant literature and consulted the research results in the related fields both at home and abroad, and conveyed the requirements and attention to each of the students, and gave a detailed explanation and illustration of the think-aloud protocols. After the students understood, each student was asked to translate a small paragraph, and rehearse the thinkaloud protocols, and appropriate adjustments were made to students' specific problems in the process of translation.

Implementation stage: This experiment was carried out in the audio classroom with recording equipment, and the subjects were provided with dictionary and reference books and other auxiliary materials. The experiment did not have time limit.

(4)The Data Collected in This Experiment Included the Translated Version and the Think-Aloud Data of the Students.

The author encoded the collected translations, for example, P1-T1 showed the subject 1' translation of experimental material 1 and so on. In addition, after the end of the experiment, the author immediately transcribed the thinkaloud data, including reading of the original text, pause, repetition, and review of dissenting part on the spot. 


\section{DATA ANALYSIS AND DISCUSSION}

\section{A. Reliability Analysis of Data}

In order to verify that the think-aloud protocols did not have a significant impact on the completion of translation tasks, the author first analyzed the time taken by the subjects to complete the entire translation task and the pause time in the process in the form of percentage(Table 2). In addition, the author also asked the subjects to complete a questionnaire immediately after completing the task. (Table 3) four questions were as follows:

1) How many thinking processes of translating texts do I record in the translation process?( )

\section{A $90 \%$ B $70 \%$ C $50 \%$ D $30 \%$}

2)How much influence do I think think-aloud protocols have on my translation?

A Extremely large B Very large C Some D Not

3)In the process of think-aloud training, my brain state ( )

A Very good B Fairly good C Not bad D Not good

4)I think the experimental environment( ).

A Very good B Good C Not bad D Not good

TABLE II. A DESCRIPTION OF THE THIRTY-FIVE SUbJECTS' TIME DURATION OF TASK FulFiLlmENT

\begin{tabular}{|c|c|c|c|}
\hline Participants & Time(min) & Pause(min) & Percentage (\%) \\
\hline 30 & 2.4 & 8 & \\
\hline $\mathrm{P} 2$ & 43 & 2 & 4.65 \\
\hline $\mathrm{P} 3$ & 37.5 & 1.55 & 4.13 \\
\hline P4 & 30 & 2.77 & 3.25 \\
\hline P5 & 34 & 2.8 & 8.23 \\
\hline P6 & 23.9 & 2.07 & 8.66 \\
\hline P7 & 38 & 3.67 & 9.65 \\
\hline P8 & 29 & 2.4 & 8.27 \\
\hline P9 & 35 & 2.9 & 8.28 \\
\hline P10 & 28 & 2.6 & 9.28 \\
\hline $\mathrm{P} 11$ & 34 & 2.39 & 7 \\
\hline $\mathrm{P} 12$ & 36 & 2.63 & 7.3 \\
\hline $\mathrm{P} 13$ & 26 & 2.5 & 9.6 \\
\hline P14 & 25 & 1.5 & 6 \\
\hline P15 & 28 & 2.23 & 7.9 \\
\hline P16 & 41 & 2.49 & 6.07 \\
\hline $\mathrm{P} 17$ & 39 & 1.25 & 3.2 \\
\hline P18 & 27 & 1 & 3.7 \\
\hline $\mathrm{P} 19$ & 25.5 & 1.39 & 5.45 \\
\hline $\mathrm{P} 20$ & 40 & 2.8 & 7 \\
\hline $\mathrm{P} 21$ & 29 & 1.45 & 5 \\
\hline $\mathrm{P} 22$ & 47.5 & 3.3 & 6.9 \\
\hline $\mathrm{P} 23$ & 28 & 1.26 & 4.5 \\
\hline $\mathrm{P} 24$ & 33.5 & 2.47 & 7.3 \\
\hline $\mathrm{P} 25$ & 45 & 3.35 & 7.4 \\
\hline $\mathrm{P} 26$ & 34.5 & 2.9 & 8.4 \\
\hline $\mathrm{P} 27$ & 46.7 & 4.3 & 9.2 \\
\hline $\mathrm{P} 28$ & 26 & 1.36 & 5.2 \\
\hline P29 & 34 & 2.24 & 6.5 \\
\hline P30 & 26 & 2.06 & 4.85 \\
\hline
\end{tabular}

From the percentage analysis in Table 2, the pause time of all students in the entire translation process does not exceed $10 \%$ of the time spent, and $90 \%$ of the students' attention is focused on the translated text. Therefore, it can be concluded that the think-aloud protocols have little effect on the time students spend on translating text. 
TABle III. Thirty-Five Subjects'Responses to Questionnaire (NumberofSubJects/ Percentage)

\begin{tabular}{|ccccc|}
\hline & Q1 & Q2 & Q3 & Q4 \\
\hline A & $3(10 \%)$ & $0(0 \%)$ & $5(17 \%)$ & $8(26 \%)$ \\
B & $11(36 \%)$ & $3(30 \%)$ & $8(26 \%)$ & $8(26 \%)$ \\
C & $7(24 \%)$ & $20(47 \%)$ & $12(40 \%)$ & $14(48 \%)$ \\
D & $9(30 \%)$ & $7(23 \%)$ & $5(17 \%)$ & $0(0 \%)$ \\
\hline
\end{tabular}

It can be seen from the percentage of the translated text thinking process recorded by the students that the influence of the think-aloud protocols on students is not as great as we think. Moreover, in this process, the student" brain state is even better than usual, and the experimental environment has almost no side effects on their translation process.

\section{B. Data Coding}

Think-aloud protocol is the most important part of this experiment. Encoding these data is a time-consuming and labor-intensive task. For the author, it is his first time to be exposed to this project and he has insufficient experience in all aspects. Therefore, in this experiment, according to the characteristics of Chinese students, the author decided to use symbols instead of the translation strategy indicators proposed by Kiraly, and analyze the frequency of students using certain strategies in the translation process from the following four stages: PhI preparation stage; PhII Implementation phase; PhIII modification phase and PhIV evaluation phase. In the process of analyzing the data, the author found that in the translation process, in addition to the 20 translation strategies frequently used by German students, Kiraly also used the other seven translation strategies: S21 reading through the original text firstly; S22 delay strategy; S23 repeatedly reading the expression of a sentence in the original text; S24 logical derivation; S25 trying to countermeasure; S26 induction, and summary; S27 self-correction.

TABLE IV. EXAMPLE OF THE STATISTICS OBTAINED FROM THE PROTOCOLS

\begin{tabular}{|c|c|c|c|c|c|c|}
\hline Translation strategy & frequen & & $\mathrm{PhI}$ & PhII & PhIII & PhIV \\
\hline S1 & 9 & & & & $\sqrt{ }$ & \\
\hline S2 & 3 & & & $\sqrt{ }$ & & \\
\hline S3 & 0 & & & & & $\sqrt{ }$ \\
\hline S4 & 3 & & & & $\sqrt{ }$ & \\
\hline S5 & 1 & & & & $\sqrt{ }$ & \\
\hline S6 & 6 & & & $\sqrt{ }$ & & \\
\hline S7 & 7 & & $\sqrt{ }$ & & & \\
\hline S8 & 6 & & & $\sqrt{ }$ & & \\
\hline S9 & 1 & & & & & $\sqrt{ }$ \\
\hline S10 & 9 & & & & $\sqrt{ }$ & \\
\hline S11 & 4 & & & & & $\sqrt{ }$ \\
\hline S12 & 0 & & & $\sqrt{ }$ & & \\
\hline S13 & 3 & & & & $\sqrt{ }$ & \\
\hline S14 & 1 & & & $\sqrt{ }$ & & \\
\hline S15 & 2 & & & & $\sqrt{ }$ & \\
\hline S16 & 1 & & & & & $\sqrt{ }$ \\
\hline S17 & 2 & & $\sqrt{ }$ & & & \\
\hline S18 & 3 & & & & & $\sqrt{ }$ \\
\hline S19 & 7 & & & $\sqrt{ }$ & & \\
\hline S20 & 4 & & & $\sqrt{ }$ & & \\
\hline S21 & 1 & & $\sqrt{ }$ & & & \\
\hline S22 & 3 & & & $\sqrt{ }$ & & \\
\hline S23 & 5 & & $\sqrt{ }$ & & & \\
\hline S24 & 3 & & & & $\sqrt{ }$ & \\
\hline S25 & 2 & & & & $\sqrt{ }$ & \\
\hline S26 & 4 & & & & $\sqrt{ }$ & \\
\hline S27 & 1 & & & & & $\sqrt{ }$ \\
\hline Total & 91 & 15 & 30 & 36 & 10 & \\
\hline
\end{tabular}

The data in the above table shows that students are more likely to use translation strategies in the second and third phases of the translation process. At the same time, the author further compares the two translations and finds that the easier it is for students to use translation strategies when they encounter the more difficult content to translate. The translation process itself is a process of solving problems, so this experiment can prove that students can solve the difficulties they encounter in the translation process by using translation strategies in the translation process. 


\section{Discussion}

This experiment analyzes the use of translation strategies in the process of translation and its functions through the think-aloud protocols. At the same time, the author compares the translation process of each student horizontally, and finds that there are three factors that influence the students' choice of translation strategies.

\section{1) Translation Experience}

Translation is not just a simple conversion between words and words from one language to another. The process of translation is the process in which the translator transforms the semantic content carried by the two languages, that is, from the semantics to the style, the most appropriate and most natural equivalents in the translated language are used to reproduce the information of the primitives. Chinese and English are two completely different language systems, and verbatim translations are absolutely incompatible with translation standards. Therefore, in the process of translation, for how to make the target language and the source language functionally equivalent in meaning and form, the choice of translation strategy is very important. In the experiment, the author found that some students have insufficient translation experience and can't recognize the difference between the two languages, which makes them unable to correctly select translation strategies and affect the quality of translation.

\section{2) Language Ability}

The language ability that is leaked out during the translation process is in fact largely a student's usual writing ability. In the experiment, the author found that the texts translated by students with strong writing ability are obviously better than other students. Students with poor language skills can't do semantic coherence and can't achieve inter-language coherence. They can't skillfully use translation strategies, so the translated text is hard to understand.

\section{3) Self-confidence}

Students' self-confidence during translation also influences their choice of translation strategies. In the process of students using think-aloud protocols to transfer, the author finds that some students are very confident. Whether they encounter difficult words or sentences, they can actively find ways to transform various translation strategies to solve problems. However, there are still some students who start to sigh when they encounter difficult-to-translate content. This negative attitude is not conducive to their choice of the correct translation strategy to solve their difficulties.

\section{CONCLUSION}

The think-aloud translation method provides a way for people to study the translation process from a psychological perspective. More and more scholars use this method to find more translation strategies, translation units and factors that affect translation. As we all know, "among the five skills of English listening, speaking, reading, writing and translating, translation skills occupy a considerable proportion. Listening, speaking and reading are the foundation of English learning. Translation and writing are the most important. They are the core of English learning." First, through the horizontal comparison of the students' translation process, teachers can teach in a targeted manner. The think-aloud protocols also help the translation teaching. Secondly, teachers can apply the think-aloud translation method to classroom teaching, asking students to express their own ideas and questions, and solve them in the classroom. This will not only help develop students' creative thinking, but also transform from traditional teaching mode to student-centered classroom teaching mode.

\section{REFERENCES}

[1] Xiaoming Wu: College English Translation Teaching Guided by Functional Equivalence Theory[J], Journal of Changchun University, 2011, 21(3).

[2] Jiannan Shi: On the Improvement of the Translation Ability of non English Majors[J], Journal of Changchun University, 2011,21(1).

[3] Jääskeläinen, R. Investigating Translation Strategies [A]. Sonja Tirkkonen-Condit and JohnLaffling(eds.). Recent Trends inEmpirical Translation Research. Joensuu: FacultyofArts, 1933. [4] Jääskeläinen, R. Think-aloud protocols [M]. In M. Baker (ed). Routledge EncyclopediaofTranslationStudies.NewYork:Routledge,2001.

[4] Kiraly, Donald Charles. Think-Aloud Protocols and Construction of a Professional Translator Self-Concept [A].inDanks,Joseph H.et al. (eds). Cognitive Processes in TranslationandInterpreting.California: Sage Publications, 1997.

[5] Kring, H.P. Translation problems and translation strategies of advanced German learnersofFrench(L2)[C].InHouse,J\&S.Blum-Kulka,1986.

[6] Krings. H. Introspection in Second Language Research [M]. Clevedon: Multilingual Matters, 1987.

[7] Ledrer,M. Latraduction aujourd'ui: Le modele inpretatif [C]. Hachette LIvre S.A, 1994 